\title{
A mediação da informação nos grupos de pesquisa e no GT3 dos ENANCIB: espaços de comunicação científica em Ciência da Informação
}

\author{
Janaina Ferreira Fialho \\ Doutora; Universidade Federal de Sergipe, São Cristvão, SE, Brasil; \\ jajafialho@gmail.com \\ Martha Suzana Cabral Nunes \\ Doutora; Universidade Federal de Sergipe, São Cristvão, SE, Brasil; \\ marthasuzana@hotmail.com \\ Telma de Carvalho \\ Doutora; Universidade Federal de Sergipe, São Cristvão, SE, Brasil; \\ telmacarvalho@yahoo.com.br
}

\begin{abstract}
Resumo: A mediação da informação, no contexto da Ciência da Informação, tem se expandido e possibilitado a criação de grupos de pesquisa com produção científica que favorece a compreensão do tema. A partir dos eventos anuais do Encontro Nacional de Pesquisa em Ciência da Informação buscou-se observar a relação das pesquisas publicadas no Grupo de Trabalho 3 da Associação Nacional de Pesquisa e Pós-Graduação em Ciência da Informação, com os grupos de pesquisa cadastrados no diretório dos grupos do Conselho Nacional de Desenvolvimento Científico e Tecnológico. Trata-se de uma pesquisa exploratória, de abordagem quantitativa; caracterizando-se como um estudo bibliométrico, realizado a partir do levantamento e da identificação no Diretório dos Grupos de Pesquisa do Conselho Nacional de Desenvolvimento Científico e Tecnológico de 38 grupos de pesquisa com o tema Mediação na área da Ciência da Informação, como também das comunicações apresentadas no Grupo de Trabalho 3. Foram analisadas 277 publicações entre os anos de 2005 a 2016. Os resultados demonstraram que a região que congrega o maior número de grupos de pesquisa é a Nordeste (15) onde boa parte ainda são recentes, com 1 a 4 anos de existência (42\%). Do total dos 38 grupos analisados, 27 estiveram envolvidos com publicações de trabalhos no Encontro Nacional de Pesquisa em Ciência da Informação, ao longo de 11 edições, em um total de 144 trabalhos publicados. Considera-se que boa parte dos grupos de pesquisa encontra-se ativa e em sintonia com o que demandam as instituições de ensino superior e agências de fomento quando vinculam a produção científica ao incentivo às pesquisas, o que fortalece a compreensão da mediação como um tema transversal que cerca os diferentes fazeres dos profissionais da informação.
\end{abstract}

Palavras-chave: Mediação. Mediação da informação. Bibliometria. ENANCIB.

Grupos de pesquisa. 


\section{Introdução}

O estudo sobre a mediação da informação tem se expandido no campo da Ciência da Informação, impulsionado pelo interesse em compreender o que a condiciona e a movimenta, o que a caracteriza e a dá forma, quem dela participa, onde se estabelece sua prática de modo mais específico e quais relações estão imbricadas nela. Dentre tantas questões, as que têm como foco a mediação da informação, nas bibliotecas e em outros centros e unidades de informação, têm sido alvo dos pesquisadores vinculados à Associação Nacional de Pesquisa e Pós-Graduação em Ciência da Informação (ANCIB).

É no contexto dessa associação que ocorre, anualmente, o Encontro Nacional de Pesquisa em Ciência da Informação (ENANCIB), o qual congrega pesquisadores de todo o Brasil na disseminação de suas pesquisas já concluídas ou em andamento, que são distribuídos conforme seus temas de interesse em onze grupos de trabalho (GT).

A aglutinação de pesquisadores em torno de eventos da sua área de origem, assim como em grupos de pesquisa - tais como os que compõem o Diretório dos Grupos de Pesquisa (DGP) do Conselho Nacional de Desenvolvimento Científico e Tecnológico (CNPq) - tem sido observada como uma tendência em todos os campos de conhecimento, estimulada pela própria necessidade de sobrevivência acadêmica e de produção científica como base das políticas públicas de fomento à pesquisa nas Instituições de Ensino Superior (IES). Nesse contexto, questiona-se: qual a relação das pesquisas publicadas no GT3, da ANCIB, nos ENANCIB com os grupos de pesquisa cadastrados no DGP do CNPq?

A partir dessa questão, o objetivo geral do artigo é analisar a relação entre a produção científica do GT3 da ANCIB e os grupos de pesquisa sobre mediação do CNPq. Dentre os objetivos específicos estão: mapear os grupos de pesquisa com tema mediação na base do DGP/CNPq; analisar a produção científica do GT3; identificar a participação dos pesquisadores que compõem os grupos de pesquisa nos trabalhos publicados no GT3; compreender a influência dos grupos de trabalho na produção científica sobre mediação da informação. 
Dessa forma, para alcançar esses objetivos foi realizada uma pesquisa exploratória de abordagem quantitativa, tendo como fontes de coleta de dados o DGP/CNPq e os anais do GT3 publicados nos ENANCIB.

\section{As redes de informação e a pesquisa em Ciência da Informação no Brasil}

Como parte da atividade humana, a interação entre pessoas é indiscutível e se dá em várias frentes, por meio da comunicação pessoal, da comunicação em redes, da leitura, da participação em grupos de interesses comuns e nas relações familiares, profissionais, estudantis, acadêmicas, religiosas etc. Desde cedo, na educação familiar e mais tarde, na educação escolar, aprendemos a conviver em sociedade, respeitando suas regras de direitos e deveres. Assim, na construção de nossas competências e habilidades, participamos de sistemas sociais que, cada um com seu próprio interesse, trazem uma gama de informações que fornecerão o conhecimento necessário à nossa formação.

Nesse sentido, adentrando no mundo do conhecimento científico, será necessário desenvolvermos habilidades para entender, compreender e participar do desenvolvimento da ciência, que se dá por meio de uma formação em como fazer ciência e que deve se iniciar na idade escolar e ir se aprimorando ao longo do tempo, especialmente, na universidade e na pós-graduação, onde se incrementam as relações sociais entre pessoas, instituições, grupos de pesquisa etc. (WITTER, 2009).

$\mathrm{Na}$ academia, o grupo de pesquisa é a reunião de pessoas ligadas por interesses comuns sobre determinados temas, podendo estar regionalmente distantes, mas interligadas por sistemas de informação. Tais pessoas utilizam as tecnologias de informação e comunicação (TIC), especialmente a Internet, para a construção de redes interativas, como os grupos compreendidos no Diretório dos Grupos de Pesquisas do CNPq.

Witter (2009) enfatiza a importância de os alunos adentrarem à universidade, especialmente, nos cursos de pós-graduação, com as competências e habilidades necessárias ao fazer ciência, entretanto, salienta que muitos deles têm, na pós-graduação, essa iniciação. Para a pesquisadora, é necessário incluir os alunos de pós nas redes sociais colaborativas que, se constituídas pelo 
orientador, serão formadas por orientadores, pesquisadores, alunos de pósgraduação e alunos de graduação, e nas quais a informação será, constantemente, repassada aos interessados, que poderão estar geograficamente distribuídos e será permitida a elaboração de trabalhos individuais ou em grupos.

Salienta, ainda, que o orientador deve monitorar seu aluno, encaminhando-o para grupos de discussão, como citam Wei e Chen (2006 apud WITTER, 2009). Essa interação dos alunos de pós-graduação com as redes possibilitará o desenvolvimento de novos interesses e, consequentemente, de novas redes, onde outros pesquisadores, alunos de graduação e de pósgraduação poderão se inserir, levando seus resultados à população em geral.

Os sistemas de informação, por sua vez, apresentam características que os diferenciam uns dos outros como: “[...] conteúdo, funcionalidade, forma, técnicas, recursos, acessibilidade e mesmo teorias e desenvolvimento científicos que lhe dão sustentação [...]" (MOSTAFA; MURGUIA, 2006; SOUZA, 2006 apud WITTER, 2009, p. 187). Podem ser amigáveis, sendo de fácil acesso e envolvem fatores como: “[...] custos, qualidade, organização e qualidade da informação disponibilizada [...]" (WITTER, 2009, p. 187). A autora informa que, no Brasil, instituições como a Coordenação de Aperfeiçoamento de Pessoal de Nível Superior (CAPES) e a Fundação de Amparo à Pesquisa do Estado de São Paulo (FAPESP), além de algumas universidades, principalmente pela pósgraduação, estimulam a formação e a implementação de redes sociais de informação. Ela destaca, ainda, a importância do conhecimento das bases de dados específicas a cada área do conhecimento, especialmente a de periódicos, já que são por meio delas que ocorre a disponibilização da informação.

Marteleto (2009), por sua vez, destacou o papel das instituições de ensino superior e de ciência e tecnologia como marcos na evolução da Ciência da Informação (CI) brasileira, a exemplo do Instituto Brasileiro de Bibliografia e Documentação (IBBD) criado em 1954 e transformado em Instituto Brasileiro em Informação, Ciência e Tecnologia (IBICT) em 1976. O impulso dado à CI, a partir das experiências e cursos desenvolvidos no IBBD, foi decisivo na formação de recursos humanos para atuar nas pesquisas do novo campo, assim 
como na criação de programas de pós-graduação e de veículos de comunicação científica, a fim de fortalecer a produção científica e contribuir para difundir a CI brasileira em âmbito nacional e internacional.

Foi no IBBD que se desenvolveram as primeiras experiências de cursos de pós-graduação em nível de especialização e de mestrado (RUSSO, 2010). Em 1970, foi criado o primeiro curso de Mestrado em Ciência da Informação com a participação de professores americanos e ingleses (MARTELETO, 2009). A institucionalização acadêmica da CI, no Brasil, mostrou-se gradativa, de acordo com Pinheiro (2007), a partir da criação de cursos e do desenvolvimento de pesquisas, os quais relacionavam temáticas, disciplinas e linhas de pesquisa que contribuíram para definir as tendências e prioridades da área como campo científico.

Além disso, destaca-se o papel desempenhado pela ANCIB, criada em 1989, como espaço de discussões em torno da Ciência da Informação, impulsionando a pesquisa na área e fomentando a realização de encontros nacionais, como o ENANCIB, que contribui para a disseminação do conhecimento científico produzido a nível da pós-graduação nacional (PINHEIRO, 2007).Nesse contexto, interessa a esse estudo a produção associada aos Grupos de Trabalho (GT) da ANCIB, em especial ao GT3 denominado Mediação, Circulação e Apropriação da Informação, que tem como ementa:

Estudo dos processos e das relações entre mediação, circulação e apropriação de informações, em diferentes contextos e tempos históricos, considerados em sua complexidade, dinamismo e abrangência, bem como relacionados à construção e ao avanço do campo científico da Ciência da Informação, compreendido em dimensões inter e transdisciplinares, envolvendo múltiplos saberes e temáticas, bem com contribuições teórico-metodológicas diversificadas em sua constituição. (ASSOCIAÇÃO..., 2016).

Criado em 2005, sob a denominação Mediação, Circulação e Uso da Informação, esse GT vem evoluindo, denominando-se, desde 2009, como Mediação, Circulação e Apropriação da Informação e apresentando, segundo Gomes (2010), algumas tendências, dentre elas o debate dos temas sobre a 
mediação humana em toda a sua complexidade, fundamentando as bases teórico-metodológicas que têm norteado as publicações, seja nos periódicos da área ou nos Encontros promovidos pela ANCIB.

Uma outra tendência observada por Gomes (2010) é a interseção de temáticas, nos trabalhos apresentados no GT3, entre os anos de 2008 e 2009, indicando a discussão de temas que são pertinentes aos objetivos do GT3, ainda que, em outros casos, alguns trabalhos possam ser considerados correspondentes às temáticas de outros GTs, a exemplo do GT4 (Gestão da Informação e do Conhecimento), do GT7 (Produção e Comunicação da Informação em Ciência, Tecnologia \& Inovação) ou mesmo do GT8 (Informação e Tecnologia). Essa constatação reforça, segundo a autora, a necessidade de se repensar as sessões temáticas do ENANCIB, de forma a atender aos temas considerados transversais, que possam articular e congregar pesquisadores de diferentes GTs em torno de pesquisas comuns. Antes da apresentação dos resultados da pesquisa que esse artigo propõe, segue-se uma exposição sobre a mediação da informação, tema central do GT3.

\section{Mediação da informação}

A mediação da informação, tal qual vem sendo estudada na Ciência da Informação e na Biblioteconomia, caracteriza-se como um processo que engloba diferentes atores, saberes, dispositivos, ambientes e sistemas, interligados pelo interesse, pela informação, pelo desejo do conhecimento e pela aprendizagem que permeia todas as suas interfaces.

A partir dessa constatação, vários autores têm contribuído para conceituar a mediação da informação e, dentre eles, Almeida Júnior é um dos seus defensores. Segundo o autor, a mediação pode se dar de modo explícito, quando pressupõe a interação direta entre usuário e profissional da informação, ou de modo implícito, quando o processo de mediação ocorre nas atividades de organização e tratamento da informação, sem a presença direta do usuário. Em todos os casos, Almeida Júnior (2015) entende a mediação como: 
informacionais -, direta ou indireta; consciente ou inconsciente; singular ou plural; individual ou coletiva; visando a apropriação de informação que satisfaça, parcialmente e de maneira momentânea, uma necessidade informacional, gerando conflitos e novas necessidades informacionais. (ALMEIDA JÚNIOR, 2015, p. 25).

Essa reformulação do conceito, anteriormente apresentado em um artigo publicado em 2009 (ALMEIDA JÚNIOR, 2009), apresenta a possibilidade de estender a abrangência da mediação, considerando que o alcance do trabalho com a informação não se restringe apenas aos espaços onde se encontram os acervos e os documentos que suportam a informação, mas abrange também uma perspectiva ilimitada, à qual o autor caracteriza como ambiência informacional.

Além disso, Almeida Júnior (2015) agregou ao conceito de mediação a perspectiva da incompletude que cerca o ato de se informar, diretamente relacionada à satisfação informacional do usuário, o qual compreende um ciclo que se inicia a partir da sua necessidade, mas que não se esgota nem está livre de contradições e conflitos que nele estão imbricados, gerando, continuamente, novas demandas e necessidades. Ao abordar as dimensões da mediação da informação, Gomes (2014) explora esse conceito como:

[...] uma comunicação centrada na relação dialógica, caracterizandose como uma ação compartilhada e colaborativa, na qual o profissional da informação desempenha o papel de agente mediador, mas não representa o único agente desse processo de comunicação. (GOMES, 2014, p. 50).

Para esclarecer as quatro dimensões sobre as quais se apoia o ato de mediar a informação, Gomes (2014) fundamenta sua base discursiva na dialogia que cerca o processo de mediação, considerando que ela não existe sem essa dimensão que permite a discussão, o diálogo e a interação entre sujeitos, com vistas a promover uma transformação que leve, ambos - profissionais e usuários - à consciência de seu protagonismo social.

A dimensão estética caracteriza a representação da beleza que está compreendida no ato de mediar e que oferece conforto, prazer, sentimento de pertença a quem lhe experimenta. Essa dimensão concretiza-se a partir do uso de linguagens e dispositivos de comunicação que facilitem ao indivíduo atingir a 
autonomia. Sendo assim, todo esse processo não deve passar despercebido pelo profissional, ou seja, ele deve desenvolver sua sensibilidade e espírito de humildade para captar as emoções e sensações que podem ser despertadas e apresentadas pelos usuários como resultado do ato de mediar (GOMES, 2014).

Sobre as dimensões formativa e ética da mediação, Gomes (2014) afirma que elas se revelam, por um lado, na capacitação e formação de usuários e, por outro, na observação do limite que existe e que envolve a atuação profissional na mediação, o qual separa, como diz Almeida Junior (2009), de forma tênue, a intencionalidade e a manipulação. Assim, a consciência e a competência do profissional para intervir na ação mediadora são fundamentais a fim de evitar ou até minimizar a manipulação, e ambas dependem, diretamente, da sua conduta ética, caracterizando, dessa forma, a dimensão ética da mediação da informação.

Todo esse processo que caracteriza a mediação não ocorre sem a noção de significação que cerca a informação e que é possível tomar a partir de Jean Meyriat. Precursor da Ciência da Informação na França, sua obra traz a ideia de mediação como ato cercado de significados, que toma por base a informação e que está inserido no processo de comunicação que permeia a relação entre os sujeitos. Segundo Meyriat (1983), a informação é o conteúdo cognitivo de uma comunicação realizada ou possível, e esse processo que a envolve só acontece a partir do momento em que os indivíduos dão à informação uma forma inteligível, ou seja, lhes dão uma significação.

Os trabalhos de pesquisa sobre mediação tomam por base esses e outros autores, perspectivas e abordagens. Considera-se para a mediação seu caráter relacional, dialógico e a perspectiva formativa que permeia sua prática. Esses aspectos, dentre outros, movimentam as pesquisas sobre mediação da informação nas universidades brasileiras.

Segundo Bortolin e Cervantes (2014, p. i), o foco na mediação começou a ser observado nos trabalhos publicados, no Brasil, a partir de 1992, com diferentes abordagens e perspectivas, tais como: "[...] da informação, do conhecimento, do objeto cognitivo e mais recentemente do digital e da midiatização.”. As autoras destacam os trabalhos desenvolvidos na Universidade Estadual de Londrina (UEL) e que surgiram, a partir de 2001, com o projeto "A 
mediação da informação: norteadora do fazer bibliotecário" coordenado pelo professor Oswaldo de Almeida Júnior.

A discussão sobre a mediação inseriu-se entre as mudanças observadas na Ciência da Informação, principalmente, relativas às preocupações de profissionais e pesquisadores com os estudos de usuários. Essas mudanças, segundo Couzinet (2008), convergiram para a análise de vários aspectos, como a formação profissional e o fortalecimento das associações profissionais e dos veículos de difusão das pesquisas. Dentre eles, as revistas científicas, como espaços de mediação híbrida onde circulavam profissionais e pesquisadores em busca de reconhecimento para suas atividades. Observou-se, assim, uma mudança de paradigma, o qual passou a caminhar para identificar o usuário como ator no seu contexto de aprendizagem e pesquisa, transpondo-se um paradigma centrado no sistema propriamente dito para outro paradigma orientado para o indivíduo; destacando o usuário como capaz de selecionar a informação e tratá-la; relacionando-a com outro conjunto de conhecimentos; e capaz, por fim, de construir sua própria competência informacional (COUZINET, 2008).

Nesse sentido, as pesquisas sobre mediação da informação passam a ocupar os interesses dos pesquisadores das instituições de ensino superior que, para validar suas pesquisas, adotam mecanismos de circulação, comunicação e difusão científicas, muitas vezes, construídos e reconstruídos a partir das experiências desenvolvidas nos grupos de pesquisa.

Toma-se aqui a definição de grupo de pesquisa a partir do DGP do $\mathrm{CNPq}$, mesmo que ela tenha sido fornecida no fórum de perguntas frequentes disponibilizado aos frequentadores da página. Assim, o DGP entende grupo de pesquisa como:

[...] um conjunto de indivíduos organizados hierarquicamente em torno de uma ou, eventualmente, duas lideranças: -cujo fundamento organizador dessa hierarquia é a experiência, o destaque e a liderança no terreno científico ou tecnológico; -no qual existe envolvimento profissional e permanente com a atividade de pesquisa; -cujo trabalho se organiza em torno de linhas comuns de pesquisa que subordinam-se ao grupo (e não ao contrário); -e que, em algum grau, compartilha instalações e equipamentos. (COORDENAÇÃO..., 2016). 
Dito desse modo, a formação do grupo de pesquisa conta com um, ou no máximo dois líderes, e outros membros hierarquicamente dispostos que têm interesses de pesquisa comuns. Nesses grupos ocorre o compartilhamento não apenas da produção científica e geração do conhecimento, mas também há metodologias, espaços e equipamentos que são adotados e usados para o desenvolvimento das atividades do grupo.

Cada instituição é responsável pela abertura dos grupos junto ao CNPq, sendo essa prerrogativa exclusiva da IES. As informações disponibilizadas, pelo DGP, sobre cada grupo, compreendem a situação do grupo (se certificado, ou não, ou se está atualizado ou não); o ano de formação do grupo; o nome do líder (ou líderes); a área predominante; e a instituição ao qual está vinculado. Além disso, também são incluídos endereço para contato, linhas de pesquisa, recursos humanos do grupo, assim como, instituições parceiras, equipamentos e softwares pertencentes ao grupo. A vinculação da inscrição dos membros do grupo à plataforma Lattes permite construir indicadores mais precisos que contribuem para a base censitária do DGP, a partir da agregação da produção científica, tecnológica e artística dos integrantes de cada grupo cadastrado na base. Segue-se, a partir daqui, com a descrição da metodologia usada na elaboração desse trabalho, assim como a apresentação e discussão dos resultados encontrados.

\section{Metodologia}

O estudo baseia-se em pesquisa de nível exploratório e de abordagem quantitativa, caracterizando-se como um estudo bibliométrico, a partir da observação e análise da produção quantitativa de conhecimento no tema mediação da informação. Entende-se a bibliometria, conforme Spinak (1998) como a:

[...] aplicação de análise estatística para estudar as características de uso e criação de documentos; estudo quantitativo da produção de documentos como refletido nas bibliografias; aplicação de métodos matemáticos e estatísticos ao estudo do uso que se faz de livros e outros suportes dentro e entre os sistemas de bibliotecas; estudo quantitativo de unidades físicas publicadas, ou de unidades bibliográficas, ou de seus substitutos. (SPINAK, 1998, p. 141, tradução nossa). 
Conforme Spinak (1998), a cienciometria utiliza as técnicas bibliométricas para a ciência e vai além dessas técnicas, visto que também examina o desenvolvimento das políticas científicas.

\begin{abstract}
Os temas que interessam à cienciometria incluem o crescimento quantitativo da ciência, o desenvolvimento de disciplinas e subdisciplinas, a relação entre ciência e tecnologia, a obsolescência dos paradigmas científicos, a estrutura de comunicação entre os pesquisadores, a produtividade e criatividade dos pesquisadores, as relações entre o desenvolvimento científico e o crescimento econômico etc. (SPINAK, 1998, p. 42, tradução nossa).
\end{abstract}

Tomou-se como parâmetro inicial a base de grupos de pesquisa disponibilizada pelo DGP do CNPq, em um total de 38 grupos de pesquisa com o tema Mediação na área da Ciência da Informação. Além disso, foram investigadas as comunicações apresentadas nos ENANCIB, especificamente, aquelas comunicações vinculadas ao GT3 - Mediação, Circulação e Apropriação da Informação - e publicadas nos anais dos eventos, desde a primeira edição, onde esse Grupo de Trabalho figurou, pela primeira vez, com uma denominação um pouco diferente ao início (Mediação, Circulação e Uso da Informação) em 2005. Desse modo, foram analisadas 277 publicações relacionadas ao GT3 da ANCIB entre os anos de 2005 a 2016.

A pesquisa realizada a partir do termo de busca "mediação", sem aplicação de nenhum filtro, solicitando apenas os grupos certificados pelo $\mathrm{CNPq}$, mostrou, em consulta parametrizada, um total de 776 grupos de pesquisa. O refinamento dessa busca foi empregado a fim de obter-se uma resposta mais detalhada a respeito dos grupos com o tema mediação, porém, compreendidos na grande área Ciências Sociais e Aplicadas e na área Ciência da Informação, resultando nos 38 grupos.

Nos procedimentos bibliométricos, a fim de se proceder à análise quantitativa das informações, foram analisadas as seguintes variáveis: a) distribuição dos grupos de pesquisa por região do Brasil; b) tempo de existência dos grupos de pesquisa; c) quantitativo anual de produção no GT3 nos ENANCIB; d) quantitativo dos trabalhos apresentados no GT3 e vinculação ao 
Grupo de Pesquisa nas Instituições; e e) distribuição dos trabalhos publicados nos anais por grupos e regiões. Os dados coletados foram agrupados em gráficos, tabelas e quadros com o auxílio dos programas Excel e Word for Windows.

\section{Resultados e discussão}

Os resultados apresentados refletem a análise dos dados coletados na base referente aos grupos de pesquisa do CNPQ, assim como, nos anais do ENANCIB, de 2005 a 2015. Dos 38 grupos observados, obteve-se a distribuição dos mesmos por região do Brasil, demonstrada no gráfico 1:

Gráfico 1 - Distribuição dos grupos de pesquisa sobre Mediação por região, Brasil, 2016.

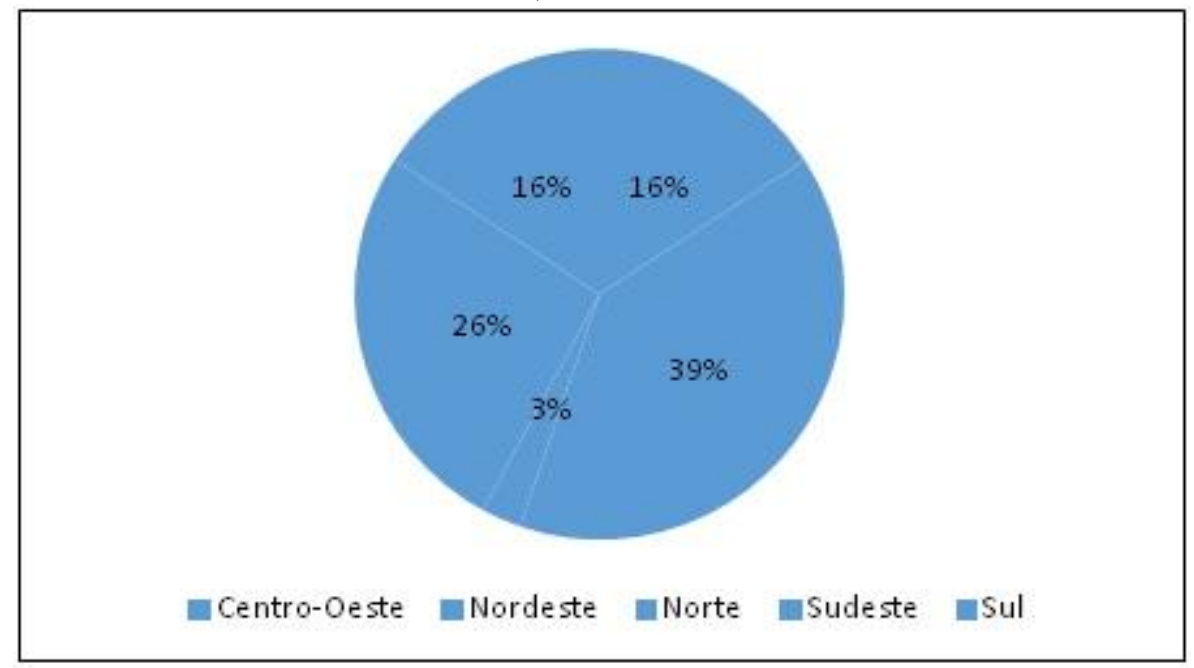

Fonte: Conselho Nacional... (2016).

Oliveira (2009), quando analisou a constituição e características dos grupos de pesquisa em Ciência da Informação no Brasil, percebeu maior concentração de grupos na região Sudeste. Segundo a autora, essa ênfase decorreu, à época de seu estudo, da maior concentração de programas de pósgraduação e centros de pesquisa em CI naquela região. Tal realidade vem se tornando mais equilibrada, visto o aumento expressivo de programas criados, mais recentemente, na região Nordeste, possibilitando a criação de novas linhas de pesquisa sobre Mediação da Informação e, consequentemente, a presença de 
Janaina Ferreira Fialho, Martha Suzana Cabral Nunes, Telma de Carvalho

mais grupos de pesquisa. Quando a busca referiu-se ao tempo de existência dos grupos, o resultado obtido revelou o seguinte panorama (Gráfico 2):

Gráfico 2 - Tempo de existência dos grupos de pesquisa com tema mediação na área da Ciência da Informação no Brasil, 2016.

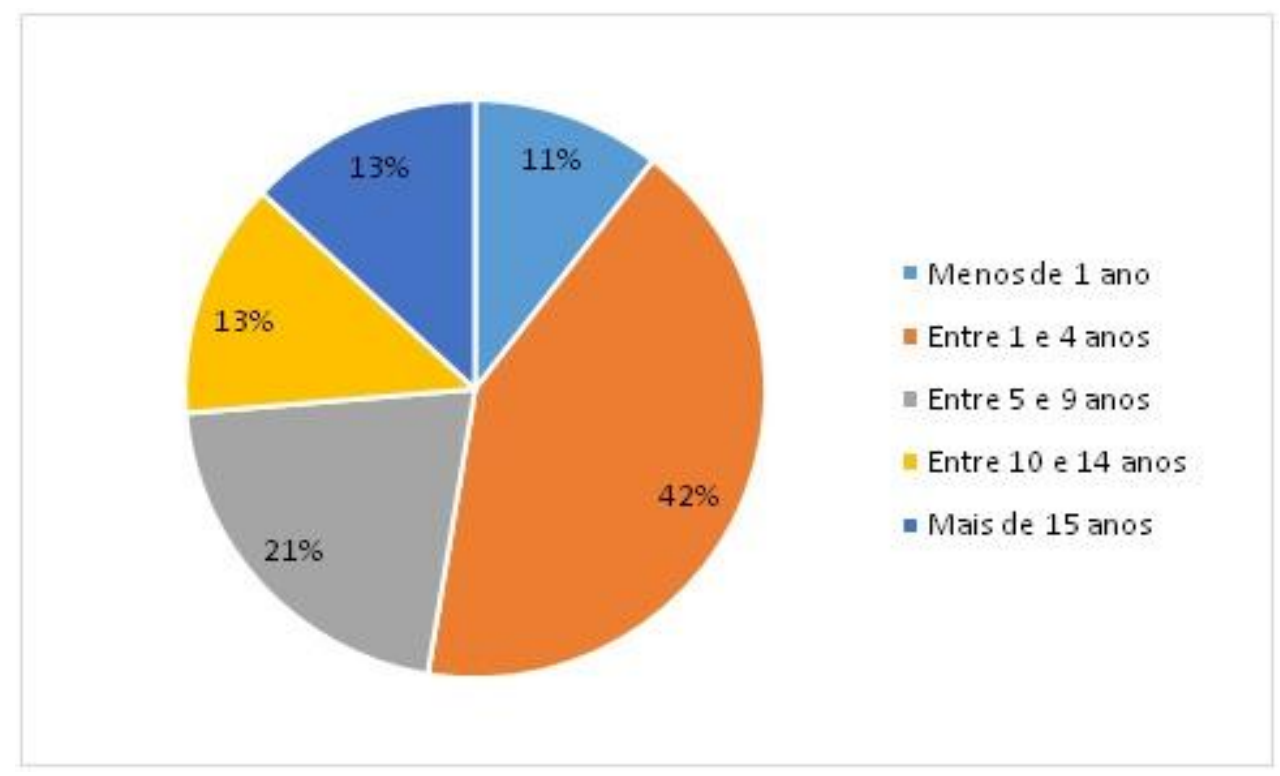

Fonte: Diretório dos Grupos CNPq (2016).

Analisando-se o gráfico 3, denota-se que boa parte dos 16 grupos de pesquisa sobre mediação da informação ainda são recentes, com 1 a 4 anos de existência (42\%). Os grupos mais antigos somam ao todo $26 \%$ do total. Dentre esses, os cinco mais antigos são:

a) grupo Difusão do Conhecimento e Apropriação dos Saberes: acesso e uso da informação na sociedade, da UFBA;

b) grupo Marketing da Informação, da UnB;

c) grupo Temma, da USP;

d) grupo Informação, Cultura e Sociedade, da UFMG;

e) grupo Interfaces: Informação e Conhecimento, da UEL.

Esses grupos com temas de pesquisa voltados para mediação situam os primeiros movimentos de pesquisa sobre o tema a partir da década de 1990, que também corresponde às mudanças paradigmáticas na área, com reflexos em estudos que se voltam para as questões que focalizam os atores do processo de 
Janaina Ferreira Fialho, Martha Suzana Cabral Nunes, Telma de Carvalho

mediação e as interfaces estabelecidas entre eles e os demais elementos que compõem esse processo. São eles: os ambientes, a comunicação, a significação, os suportes e fontes, e os dispositivos, assim como destacados por Gomes (2010), quando identificou em seu estudo, temáticas convergentes nas publicações do GT3 de 2008 e 2009, e também nas publicações de cinco periódicos da área nesse mesmo período. A totalidade dos grupos analisados, por região brasileira, pode ser visualizada no quadro 1:

Quadro 1- Grupos por região.

\begin{tabular}{|c|c|c|}
\hline Região & Nome do grupo/Instituição & Líderes \\
\hline \multirow[t]{6}{*}{$\begin{array}{l}\text { Centro- } \\
\text { oeste }\end{array}$} & $\begin{array}{l}\text { 1. Aprendizagem, Comportamento e } \\
\text { Letramento Informacional/UnB }\end{array}$ & $\begin{array}{l}\text { Kelley Cristine G. } \\
\text { Dias Gasque; Sely } \\
\text { Maria de Souza } \\
\text { Costa }\end{array}$ \\
\hline & 2. Estado, Informação e Sociedade/UnB & $\begin{array}{l}\text { Georgete Medleg } \\
\text { Rodrigues }\end{array}$ \\
\hline & $\begin{array}{l}\text { 3. Fatores Humanos na Interação e } \\
\text { Comunicação da Informação/UnB }\end{array}$ & Ivette Kafure Muñoz \\
\hline & 4. Marketing da Informação/UnB & $\begin{array}{l}\text { Sueli Angelica do } \\
\text { Amaral }\end{array}$ \\
\hline & 5. Publicações Eletrônicas/UnB & $\begin{array}{l}\text { Fernando César Lima } \\
\text { Leite; } \\
\text { Sely Maria de Souza } \\
\text { Costa }\end{array}$ \\
\hline & 6. Competência em informação/UnB & $\begin{array}{l}\text { Elmira Luzia Melo } \\
\text { Soares Simeão; } \\
\text { Aurora Cuevas } \\
\text { Cerveró }\end{array}$ \\
\hline Nordeste & $\begin{array}{l}\text { 7. Biblioteca, Informação e Sociedade } \\
\text { /UFCA }\end{array}$ & $\begin{array}{l}\text { Maria Cleide } \\
\text { Rodrigues } \\
\text { Bernardino; } \\
\text { Francisca Pereira dos } \\
\text { Santos }\end{array}$ \\
\hline
\end{tabular}


Janaina Ferreira Fialho, Martha Suzana Cabral Nunes, Telma de Carvalho

\begin{tabular}{|c|c|}
\hline $\begin{array}{lccr}\text { 8. Ciência da } & \text { Informação: Cognição, } \\
\text { Mediação } & \text { e } & \text { Construção } & \text { do } \\
\text { Conhecimento/UFBA } & & \end{array}$ & Aida Varela Varela \\
\hline $\begin{array}{l}\text { 9. Competência e Mediação em Ambientes de } \\
\text { Informação/UFC }\end{array}$ & $\begin{array}{l}\text { Maria Giovanna } \\
\text { Guedes Farias; } \\
\text { Gabriela Belmont de } \\
\text { Farias }\end{array}$ \\
\hline $\begin{array}{l}\text { 10. Competências Profissionais e Produção } \\
\text { do } \quad \text { Conhecimento } \\
\text { Contemporaneidade/UFBA }\end{array}$ & $\begin{array}{l}\text { Maria Isabel de Jesus } \\
\text { Sousa Barreira }\end{array}$ \\
\hline $\begin{array}{l}\text { 11. Cultura, Gestão da Informação e } \\
\text { Sociedade/UFC }\end{array}$ & $\begin{array}{l}\text { Lidia Eugenia } \\
\text { Cavalcante } \\
\text { Jefferson Veras } \\
\text { Nunes } \\
\end{array}$ \\
\hline $\begin{array}{l}\text { 12. Difusão do Conhecimento a Apropriação } \\
\text { de Saberes: Acesso e Uso da Informação na } \\
\text { Sociedade/UFBA }\end{array}$ & $\begin{array}{l}\text { Hildenise Ferreira } \\
\text { Novo; Ivana } \\
\text { Aparecida Borges } \\
\text { Lins }\end{array}$ \\
\hline $\begin{array}{lccc}\text { 13. Grupo de } & \text { Estudos e Pesquisa } & \text { em } \\
\text { Mediação } & \text { e } & \text { Comunicação } & \text { da } \\
\text { Informação/UFBA } & & & \end{array}$ & $\begin{array}{l}\text { Henriette Ferreira } \\
\text { Gomes; } \\
\text { Raquel do Rosário } \\
\text { Santos }\end{array}$ \\
\hline $\begin{array}{l}\text { 14. Informação } \\
\text { Contemporânea/UFRN }\end{array}$ & $\begin{array}{l}\text { Eliane Ferreira da } \\
\text { Silva; Andréa } \\
\text { Vasconcelos } \\
\text { Carvalho }\end{array}$ \\
\hline $\begin{array}{l}\text { 15. Informação, Conhecimento e } \\
\text { Sociedade/IFCE }\end{array}$ & $\begin{array}{l}\text { Sara Maria Peres de } \\
\text { Morais; } \\
\text { Carlos Henrique da } \\
\text { Silva Sousa }\end{array}$ \\
\hline $\begin{array}{l}\text { 16. Laboratório de Estudos Métricos na } \\
\text { Web/UFAL }\end{array}$ & $\begin{array}{l}\text { Ronaldo Ferreira de } \\
\text { Araújo }\end{array}$ \\
\hline
\end{tabular}


Janaina Ferreira Fialho, Martha Suzana Cabral Nunes, Telma de Carvalho

\begin{tabular}{|c|c|c|}
\hline & $\begin{array}{l}\text { 17. Laboratório de Investigações } \\
\text { Bakhtinianas Relacionadas à Cultura e } \\
\text { Informação/UFPE }\end{array}$ & Hélio Márcio Pajeú \\
\hline & $\begin{array}{l}\text { 18. NUCIG - Núcleo de Estudos em Ciência } \\
\text { da Informação/UFS }\end{array}$ & $\begin{array}{l}\text { Janaina Ferreira } \\
\text { Fialho }\end{array}$ \\
\hline & $\begin{array}{l}\text { 19. Núcleo de Estudos em Mediação, } \\
\text { Apropriação e Gestão da Informação e do } \\
\text { Conhecimento/UFS }\end{array}$ & $\begin{array}{l}\text { Martha Suzana } \\
\text { Cabral Nunes }\end{array}$ \\
\hline & $\begin{array}{l}\text { 20. PLENA - Grupo de Pesquisa em Leitura, } \\
\text { Escrita e Narrativa: Cultura, Mediação, } \\
\text { Apresentação Gráfica, Editoração, } \\
\text { Manifestações/UFS }\end{array}$ & $\begin{array}{l}\text { Valéria Aparecida } \\
\text { Bari; } \\
\text { Glêyse Santos } \\
\text { Santana }\end{array}$ \\
\hline & $\begin{array}{l}\text { 21. Prospecção e Práxis em Gestão da } \\
\text { Informação/UFPE }\end{array}$ & Nadi Helena Presser \\
\hline Norte & 22. Mediação e Uso da Informação/UFPA & $\begin{array}{l}\text { Hamilton Vieira de } \\
\text { Oliveira }\end{array}$ \\
\hline Sudeste & 23. Biblioteca Disciplinata/USP & Giulia Crippa \\
\hline & 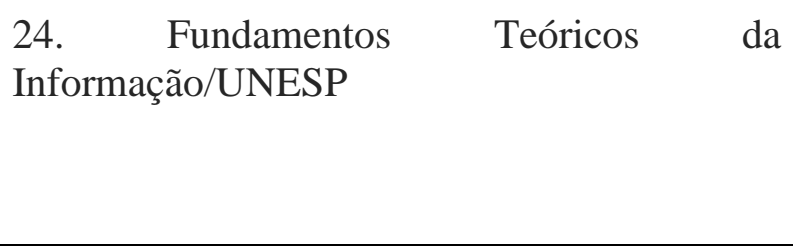 & $\begin{array}{l}\text { Carlos Cândido de } \\
\text { Almeida; } \\
\text { Daniel Martinez- } \\
\text { Avila }\end{array}$ \\
\hline & $\begin{array}{l}\text { 25. Fundamentos Teóricos, Metodológicos e } \\
\text { Históricos da Organização da } \\
\text { Informação/UFMG }\end{array}$ & Cristina Dotta Ortega \\
\hline & 26. Grupo Temma/USP & $\begin{array}{l}\text { Marilda Lopes Ginez } \\
\text { de Lara; } \\
\text { Johanna Wihelmina } \\
\text { Smit }\end{array}$ \\
\hline & $\begin{array}{l}\text { 27. Informação, Conhecimento e Inteligência } \\
\text { Organizacional/UNESP }\end{array}$ & $\begin{array}{l}\text { Marta Lígia Pomim } \\
\text { Valentin; }\end{array}$ \\
\hline
\end{tabular}


Janaina Ferreira Fialho, Martha Suzana Cabral Nunes, Telma de Carvalho

\begin{tabular}{|c|c|c|}
\hline & & $\begin{array}{l}\text { Marcia Cristina de } \\
\text { Carvalho Pazin } \\
\text { Vitoriano }\end{array}$ \\
\hline & 28. Informação, Cultura e Sociedade/UFMG & $\begin{array}{l}\text { Maria Guiomar da } \\
\text { Cunha Frota }\end{array}$ \\
\hline & $\begin{array}{l}\text { 29. Núcleo de Estudos das Mediações e Usos } \\
\text { Sociais dos Saberes e Informações em } \\
\text { Ambientes Digitais -NEMUSAD/UFMG }\end{array}$ & $\begin{array}{l}\text { Maria Aparecida } \\
\text { Moura }\end{array}$ \\
\hline & $\begin{array}{l}\text { 30. PRACTIC- Grupo de Estudos de Práticas } \\
\text { Culturais e Tecnologias de Informação e } \\
\text { Comunicação/USP }\end{array}$ & $\begin{array}{l}\text { Marco Antônio de } \\
\text { Almeida }\end{array}$ \\
\hline & 31. Práticas Informacionais/UFMG & $\begin{array}{l}\text { Adriana Bogliolo } \\
\text { Sirihal Duarte; } \\
\text { Carlos Alberto Ávila } \\
\text { Araújo }\end{array}$ \\
\hline & $\begin{array}{l}\text { 32. Usuários, Produtores e Mediadores da } \\
\text { Informação: Literacias e Comportamentos } \\
\text { Informacionais/UFSCAR }\end{array}$ & $\begin{array}{l}\text { Ariadne Chloe Mary } \\
\text { Furnival }\end{array}$ \\
\hline Sul & $\begin{array}{l}\text { 33. Acessibilidade, } \quad \text { Leitura } \\
\text { Informação/IFRS }\end{array}$ & $\begin{array}{l}\text { Lizandra Brasil } \\
\text { Estabel; } \\
\text { Eliane Lourdes da } \\
\text { Silva Moro }\end{array}$ \\
\hline & $\begin{array}{l}\text { 34. Educação à Distância e Tecnologias } \\
\text { Digitais/IFPR }\end{array}$ & $\begin{array}{l}\text { Vania Carla } \\
\text { Camargo; } \\
\text { Eduardo Fofonca }\end{array}$ \\
\hline & $\begin{array}{l}\text { 35. Informação, Conhecimento e Cultura em } \\
\text { Múltiplos Ambientes-INFOCCULT/UEL }\end{array}$ & $\begin{array}{l}\text { Luciane de Fátima } \\
\text { Beckman Cavalcante }\end{array}$ \\
\hline
\end{tabular}


Janaina Ferreira Fialho, Martha Suzana Cabral Nunes, Telma de Carvalho

\begin{tabular}{|l|lr|l|}
\hline $\begin{array}{l}\text { 36. Interfaces: Informação } \\
\text { Conhecimento/UEL }\end{array}$ & $\begin{array}{l}\text { Sueli Bortolin; } \\
\text { Oswaldo Francisco } \\
\text { de Almeida Júnior }\end{array}$ \\
\cline { 2 - 4 } & $\begin{array}{l}\text { 37. Núcleo de Estudos em Tecnologia, } \\
\text { Educação e Ciência da Informação/FASATC }\end{array}$ & Vanessa Levati Biff \\
& $\begin{array}{l}\text { 38. Representações, Memória Social e } \\
\text { Cidadania/UFRGS }\end{array}$ & Valdir Jose Morigi \\
\hline
\end{tabular}

Fonte: Elaborado pelas autoras.

Nesse conjunto, destaca-se que foram observados um total de 20 grupos com liderança de dois pesquisadores e 18 grupos com líderes individuais. Ressalta-se que, para criação dos grupos, é necessária a inclusão de, no mínimo, três pesquisadores da instituição com doutorado, para que seja preenchido o formulário de solicitação disponibilizado pelo $\mathrm{CNPq}$ à instituição, para a abertura de grupos. É importante apontar que buscou-se apresentar a produção científica não apenas dos líderes dos grupos no GT3 do ENANCIB, mas também de qualquer outro membro integrante dos grupos analisados. A pesquisa sobre o nome dos pesquisadores autores deu-se por intermédio da aba "consultas-base corrente" no diretório do CNPq, consultando, diretamente, pelo nome do pesquisador no termo de busca. A busca foi aplicada nos campos de líder e pesquisador, e nenhum tipo de filtro foi aplicado, conforme é possível visualizar na figura 1. 

GT3 dos ENANCIB: espaços de comunicação científica em Ciência da Informação

Janaina Ferreira Fialho, Martha Suzana Cabral Nunes, Telma de Carvalho

Figura 1- Tela de pesquisa.

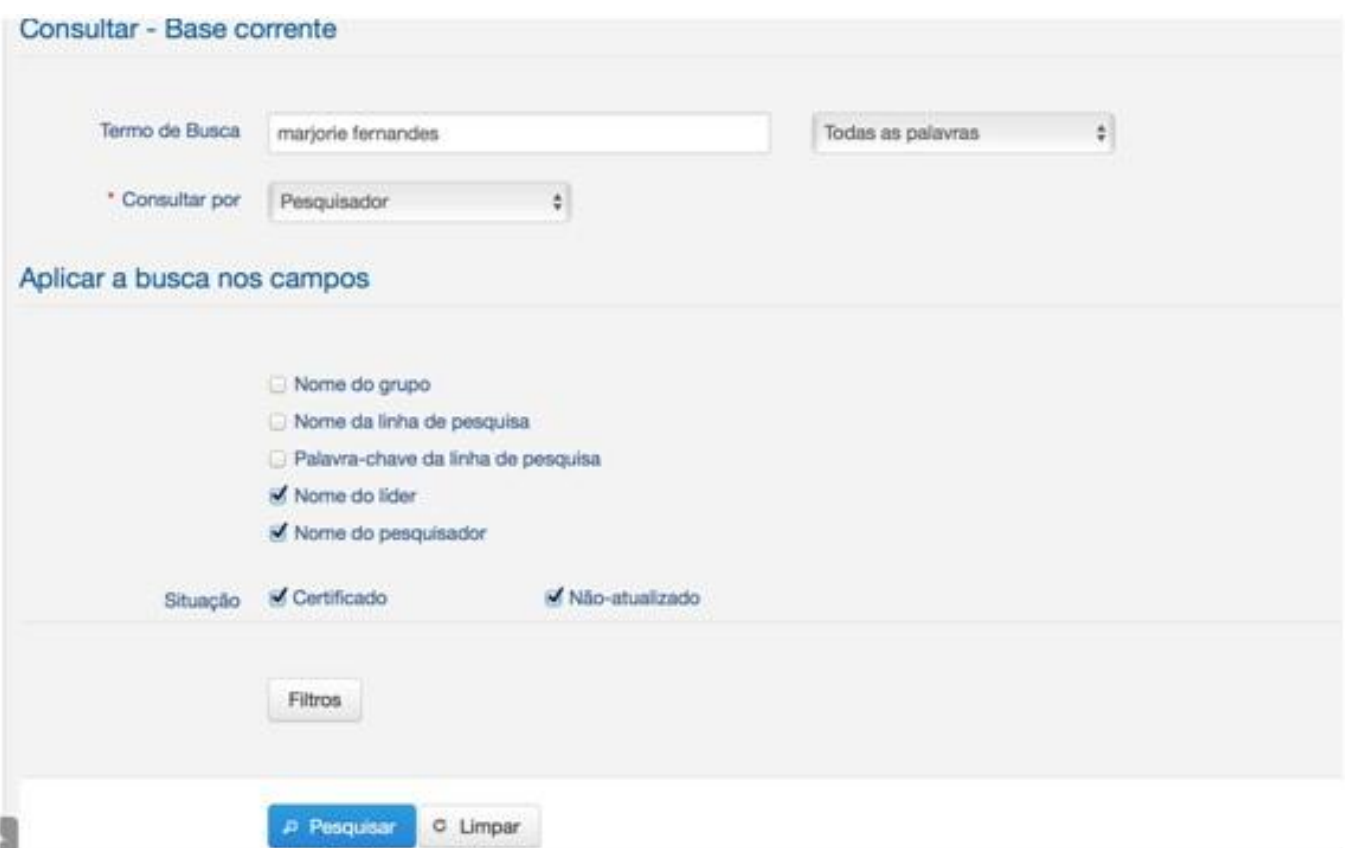

Fonte: Diretório dos Grupos CNPq (2016).

Os trabalhos apresentados no GT3 compreenderam um total de 277 (Gráfico 3), observando-se os anais das seguintes edições: VI (2005), VII (2006), VIII (2007), IX (2008), X (2009), XI (2010), XII (2011), XIII (2012), XIV (2013), XV (2014) e XVI (2015).

Gráfico 3 - Quantitativo de produção no GT3 por ano, nos ENANCIBs.

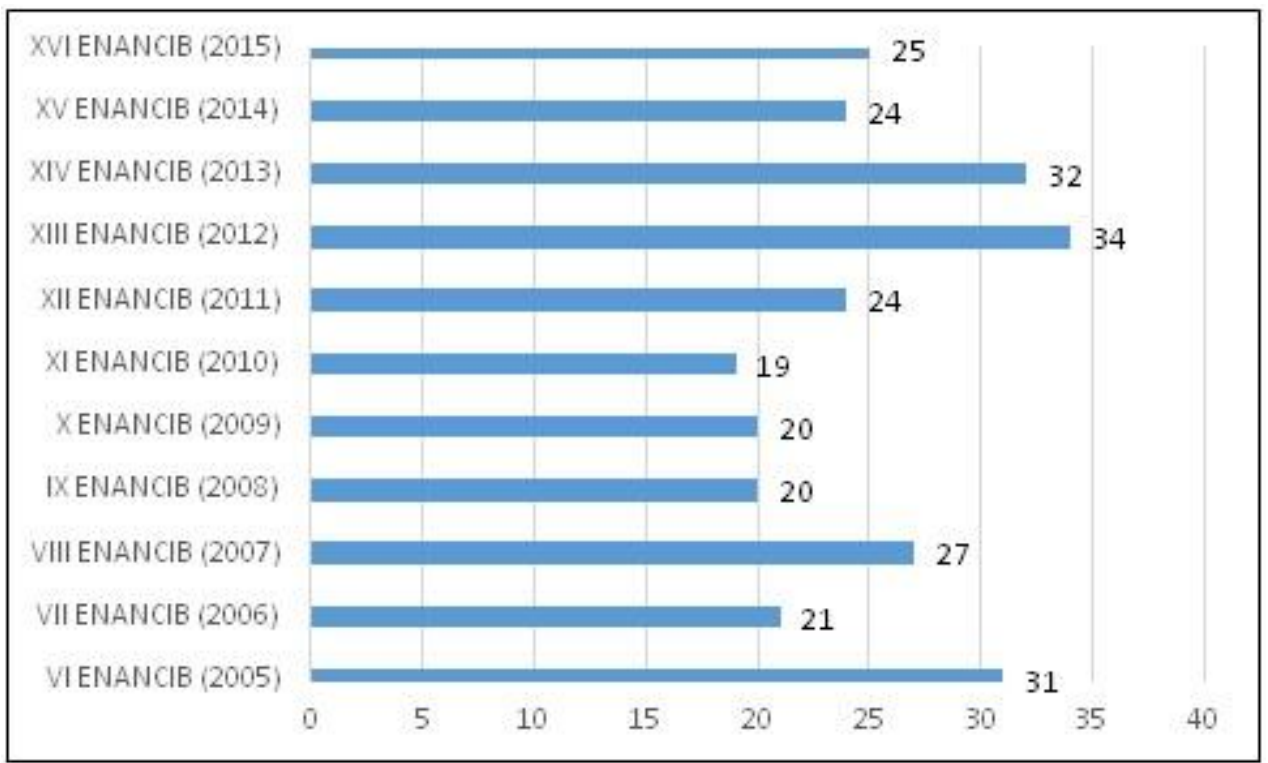

Fonte: Elaborado pelas autoras. 
Janaina Ferreira Fialho, Martha Suzana Cabral Nunes, Telma de Carvalho

Analisando-se o gráfico 3, destaca-se que a produção no GT3, ao longo do tempo, mostra-se, de certo modo, equilibrada, variando entre 2005 e 2015, entre 20 a 30 trabalhos apresentados. Há um número maior de publicações, nos anos 2005, 2012 e 2013, que pode ter sido ocasionado por motivos diversos, tais como, no caso de 2005, o ano de criação do GT, vindo, historicamente, da demanda de sua própria criação, e, nos demais anos, pelo volume de produção na área. Contudo, isso não pode ser confirmado e requer outros estudos. Usando o mesmo período de análise do gráfico 3, apesenta-se o gráfico 4 com a vinculação entre a produção no GT3 e os grupos de pesquisa encontrados no DGP sobre o tema mediação em CI.

Gráfico 4 - Quantitativo dos trabalhos apresentados no GT3 dos ENANCIB com relação à sua vinculação aos grupos de pesquisa, por instituição.

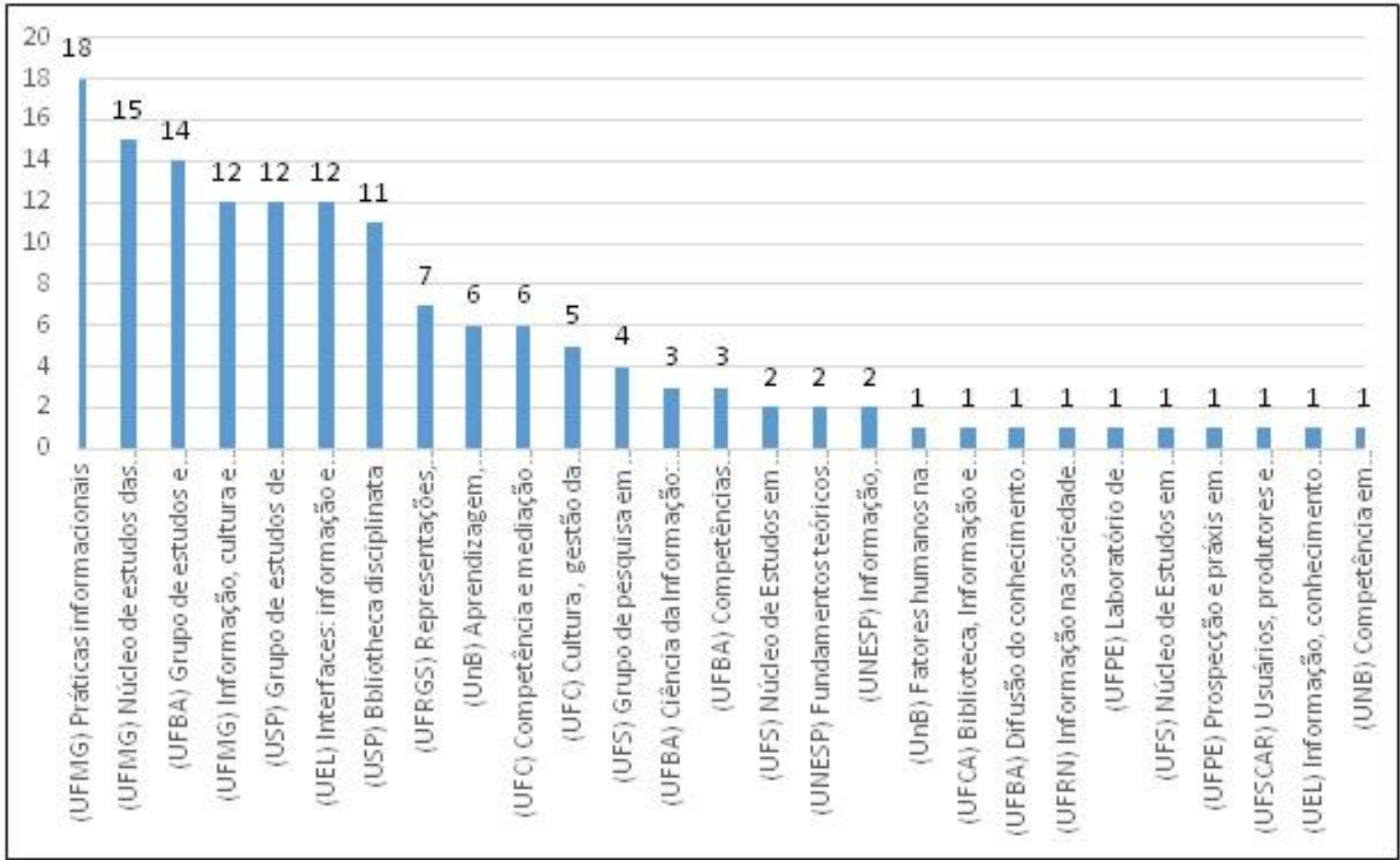

Fonte: Elaborado pelas autoras.

Observa-se que, do total de 38 grupos de pesquisa com o tema mediação do DGP/CNPq, 27 estiveram envolvidos com publicações de trabalhos no ENANCIB, ao longo de 11 edições, num total de 144 trabalhos publicados. A 
distribuição desses trabalhos por grupos e por região está apresentada no gráfico 5.

Gráfico 5 - Distribuição do quantitativo de trabalhos publicados nos anais do GT3 por grupos e por região.

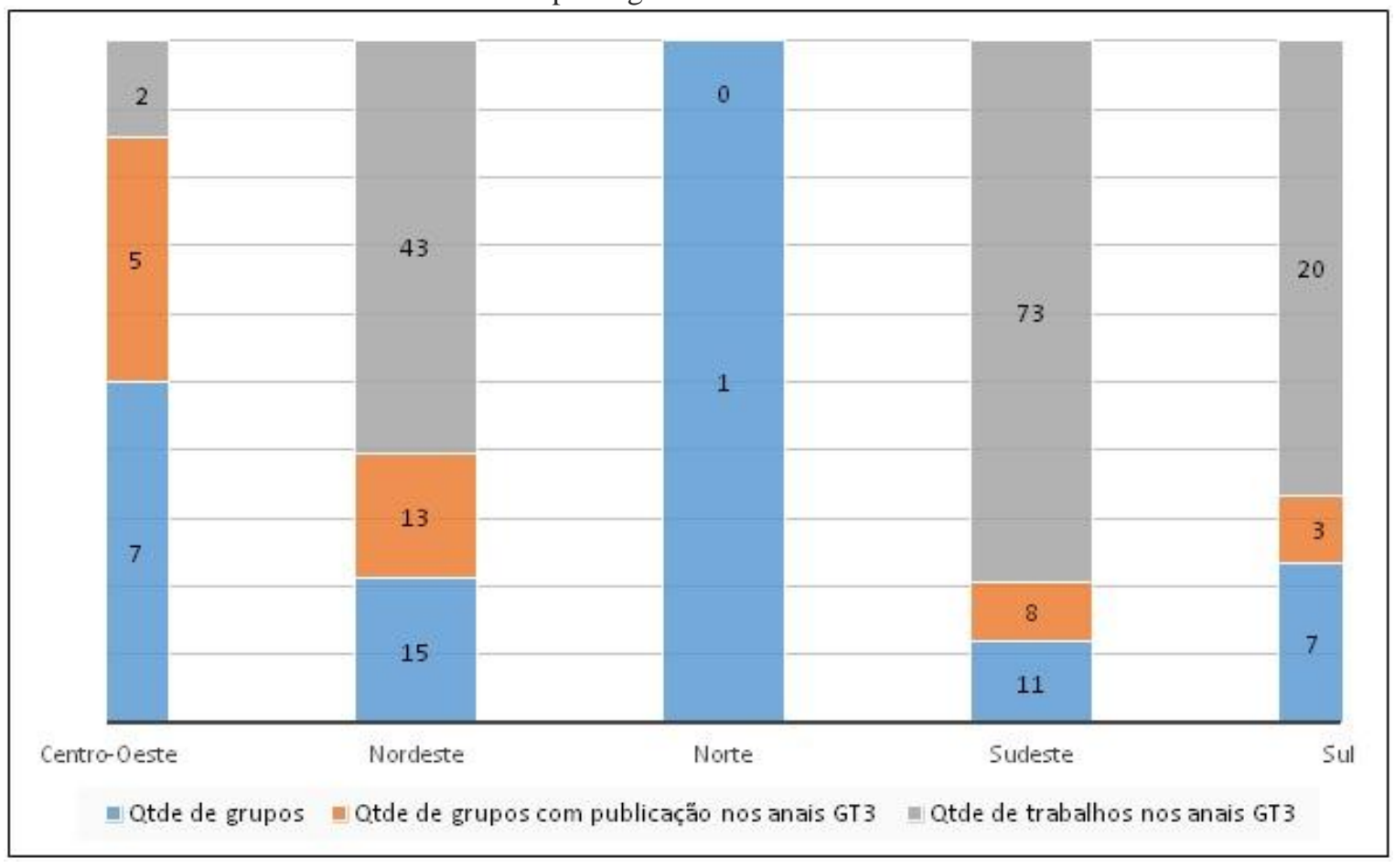

Fonte: Elaborado pelas autoras.

Os dados apresentados no gráfico 5 demonstram que, apesar de haver maior número de grupos sobre mediação na região Nordeste, na publicação de trabalhos no GT3 prevalece, quantitativamente, a região Sudeste. Esse dado reflete a pesquisa em CI, nessa região, que é histórica na criação de cursos de graduação e pós-graduação na área da CI e da Biblioteconomia e cuja experiência reflete-se nas pesquisas desenvolvidas em cursos que correspondem a mais da metade dos grupos mais antigos observados nesse estudo, como também apontados por Oliveira (2009).

É importante destacar que o quantitativo de grupos de pesquisa, no campo da Ciência da Informação, reflete a demanda pela pesquisa e a produção científica nos últimos anos, pelas agências financiadoras públicas, a exemplo de CAPES, CNPq e fundações de apoio à pesquisa em nível estadual, que estabelecem critérios de distribuição de recursos e priorizam investimentos em 
áreas estratégicas para o desenvolvimento da Ciência, da Tecnologia e da Inovação no Brasil (SANTANA et al., 2014).

Por fim, observou-se que a distribuição geográfica dos grupos tem se concentrado, em sua maioria, na região Nordeste, e que o ENANCIB ainda é um dos grandes espaços de disseminação da produção científica sobre mediação da informação no Brasil.

\section{Considerações finais}

Após as análises empreendidas, considera-se que ocorre uma relação direta entre as produções dos grupos de pesquisa com tema mediação e os trabalhos apresentados no GT3. De um total de 277 trabalhos apresentados, ao longo das 11 edições do ENANCIB, 144 deles estavam vinculados a 27 dos 38 grupos de pesquisa que foram analisados nesse artigo.

Esses dados demonstram, de modo claro, que boa parte dos grupos de pesquisa encontra-se ativo e em sintonia com o que demandam as IES e as agências de fomento quando vinculam a produção científica de fomento às pesquisas, mesmo que isso represente, muitas vezes, diminuição do tempo do pesquisador para dedicar-se aos seus trabalhos de forma mais direta, uma vez que ele precisa se dividir entre o ensino e a extensão, para além da tarefa da pesquisa.

Além disso, outras pesquisas mostraram a tendência na formação de novos grupos na área da Ciência da Informação, o que também foi observado neste estudo, visto que a maior parte dos grupos de pesquisa analisados encontra-se com tempo de existência entre 1 a 4 anos, o que leva a inferir que são grupos que buscam firmar-se dentre os já consolidados e refletem, outrossim, a formação de novos pesquisadores e a expansão da pós-graduação na área, em especial, em regiões fora do eixo Sul-Sudeste, a exemplo da região Nordeste.

De outro modo, a pesquisa pode ainda ser ampliada para observar aspectos referentes aos temas, metodologias e paradigmas que mais têm influenciado as publicações dos grupos de pesquisa que estudam mediação da informação no Brasil, e o impacto da criação desses grupos na formação de 
novos elos nas redes de conhecimento que se constroem e reconstroem entre os pesquisadores da mediação da informação pelos diferentes centros de pesquisa no país. Além disso, deixa aberta a possibilidade de realizar estudos que aprofundem a relação autor, instituição e redes de colaboração científica.

Esses elos reforçam a construção epistemológica e metodológica da área, contribuindo para fortalecer a compreensão da mediação como um tema transversal e que cerca os diferentes fazeres dos profissionais da informação, além de ampliar a capacidade de explorar potencialidades e transformar as realidades dos sujeitos envolvidos nesse processo complexo que se denomina mediação da informação.

\section{Referências}

ALMEIDA JÚNIOR, Oswaldo Francisco de. Mediação da informação: um conceito atualizado. In: BORTOLIN, Sueli; SANTOS NETO, João Arlindo; SILVA, Rovilson José da (Org.). Mediação oral da informação e da leitura. Londrina: ABECIN, 2015. p. 9-32.

ALMEIDA JÚNIOR, Oswaldo Francisco de. Mediação da informação e múltiplas linguagens. Pesquisa Brasileira em Ciência da Informação, Brasília, v. 2, n. 1, p. 89-103, jan./dez. 2009.

ASSOCIAÇÃO NACIONAL DE PESQUISA E PÓS-GRADUAÇÃO EM CIÊNCIA DA INFORMAÇÃO. GT3-ementa. 2016. Disponível em: <http://gtancib.fci.unb.br/index.php/gt-03>. Acesso em: 6 ago. 2016.

BORTOLIN, Sueli; CERVANTES, Brígida Maria Nogueira. Editorial. Informação \& Informação, Londrina, v. 19, n. 2, maio/ago. 2014.

CONSELHO NACIONAL DE DESENVOLVIMENTO CIENTÍFICO E TECNOLÓGICO. CNPq. Diretório dos Grupos de Pesquisas. 2016. Disponível em: 〈http://dgp.cnpq.br/dgp/faces/consulta/consulta_parametrizada.jsf>. Acesso em: 20 jul. 2016.

COUZINET, Viviane. Vers une "société du savoir": approche ethnoinformationnelle de la «culture de l'information». The Scientific Annals of «Alexandru Ioan Cuza » University of Iasi Communication Science, Iasi, v. 1, n. 1, 2008, p. 83-98.

GOMES, Henriette Ferreira. A dimensão dialógica, estética, formativa e ética da mediação da informação. Informação \& Informação, Londrina, v. 19, n. 2, p. 46-59, maio/ago. 2014. 
GOMES, Henriette Ferreira. Tendências de pesquisa sobre mediação, circulação e apropriação da informação no Brasil: estudo em periódicos e Anais dos ENANCIB (2008-2009). Pesquisa Brasileira em Ciência da Informação, Brasília, v. 3, n. 1, p. 85-99, jan./dez. 2010.

MARTELETO, Regina Maria. A pesquisa em Ciência da Informação no Brasil: marcos institucionais, cenários e perspectivas. Perspectivas em Ciência da Informação, Brasília, v. 14, n. esp., p. 19-40, 2009.

MEYRIAT, Jean. De la Science de l'Information aux métiers de l'Information. Schéma et Schématisation, Noyers-sur-Serein, n. 19, p. 65-74, 1983.

OLIVEIRA, Marlene de. Grupos de pesquisa em Ciência da Informação no Brasil. Pesquisa Brasileira em Ciência da Informação, Brasília, v. 2, n. 1, p. 38-59, jan./dez. 2009.

PINHEIRO, Lena Vania Ribeiro. Cenário da pós-graduação em Ciência da Informação no Brasil, influências e tendências. In: ENCONTRO NACIONAL DE PESQUISA EM CIÊNCIA DA INFORMAÇÃO, 8., 2007, Salvador. Anais...Salvador: EDUFBA, 2007.

RUSSO, Mariza. Fundamentos de Biblioteconomia e Ciência da Informação. Rio de Janeiro: E-papers, 2010. 178p.

SANTANA, Guilherme Alves de et al. Indicadores dos grupos de pesquisa da área de Gestão da Informação na Região Nordeste: um enfoque para a colaboração em artigos de periódicos. Em Questão, Porto Alegre, v. 20, n. 3, ed. esp., 2014.

SPINAK, Ernesto. Indicadores cienciometricos. Ciência da Informação, Brasília, v. 27, n. 2, p. 141-148, maio/ago. 1998.

WITTER, Geraldina Porto. Redes sociais e sistemas de informação na formação do pesquisador. In: POBLACIÓN, Dinah Aguiar; MUGNAINI, Rogerio; RAMOS, Lúcia Maria S. V. Costa (Orgs.). Redes sociais e colaborativas em informação científica. São Paulo: Angellara, 2009. p. 169-201. 


\title{
Information mediation in the research groups and in the GT3 of ENANCIB: science communication spaces in Information Science
}

\begin{abstract}
Information mediation in the context of Information Science has expanded and enabled the creation of research groups with scientific production that favor the understanding of the subject. From the annual events of National Meeting Research in Information Science, we sought to observe the relationship between the research published in the Working Group 3 of National Association of Research and Pos-graduation in Information Science with the research groups registered in the directory of National Council for Scientific and Technological Development groups. This is an exploratory research with a quantitative approach, characterized as a bibliometric study carried out from the survey and the identification, in the National Council for Scientific and Technological Development Research Group Directory of 38 research groups with the theme mediation in the area of Information Science, as well as the papers presented in Working Group 3. Thus, we analyzed 277 publications between the years 2005 and 2016. The results showed that the region, which has the largest number of research groups, is the Northeast (15), where most of the groups research is still fresh, with 1 to 4 years old (42\%). Out of a 38 research groups, 27 were involved with the work publications in National Meeting Research in Information Science, over 11 editions in a total of 144 published articles. It is considered that a large number of the research groups is active and in line with the demand of higher education institutions and funding agencies, when they link scientific production to the incentive of research, which reinforces the understanding of mediation as a transversal theme that covers the different roles of the information professionals..
\end{abstract}

Keywords: Mediation. Information mediation. Bibliometrics. ENANCIB. Research groups.

Recebido em: 13/08/2016

Aceito em: 14/11/2016 